\title{
Parallel Processing of Cutaneous Information in the Somatosensory System of the Cat
}

\author{
ROBERT W. DYKES
}

RÉSUME: Dans le passé le principe de base des mécanismes corticaux du système sensitif furent fondés en grande partie sur le résultat de l'étude du système somatosensitif. Les idées de cartes topographiques de colonnes corticales, de spécificité modale, ont toutes originées dans l'étude de ce système, pour être ensuite appliquées aux systèmes auditifs et visuels. Récemment des changements fondamentaux se sont produits dans notre compréhension des fonctions somatosensitives et corticales, ces concepts nouveaux s'appliqueront bientôt aux autres systèmes. Le présent article détaille ces développements.
From the Microsurgical Research Laboratories. Departments of Neurology and Neurosurgery, Physiology and Surgery. Royal Victoria Hospital, McGill University, Montreal, Quebec.

Reprint Requests to: Dr. R.W. Dykes, Microsurgical Laboratories, Royal Victoria Hospital, McGill University, M ontreal, Quebec.
In the past, studies of the somatosensory system have played a major role in developing ideas central to understanding cortical mechanisms applicable to all sensory systems. The ideas of (i) topographic maps, (ii) cortical columns, and (iii) modality specificity originated in this sensory system and were later applied to the auditory and visual systems. Now, after several decades of relative constancy, our ideas about somatosensory cortical function have begun to change rather rapidly and again the newer ideas may find useful applications in other sensory systems. In this article the concepts found in current textbooks are summarized briefly and the many elegant experiments which expanded and filled out the details of these traditional ideas are noted only briefly so that there is space to present some of the newer ideas about the somatosensory system.

\section{THE TRADITIONAL VIEWS}

Somatosensory Maps: The Homunculus A map of the body surface spread on the postcentral gyrus was published by Penfield and Boldrey in 1937 (Fig. 1) and eventually became known as the homunculus. Woolsey and his colleagues mapped many species in the next 25 years and drew corresponding animal shapes over the postcentral gyrus or its homologue in each species studied (Woolsey, 1958; 1964). No one questioned the validity of this conceptualization. Instead, discussions focussed on the details of the organization of the maps. For example, the relationships between the orientation of the occiput, hand, and face were discussed in great length (Woolsey, 1958; Penfield and Jasper, 1954).

The existence of a second somatosensory representation in the cerebral cortex (SII) was apparent from the beginning (Adrian, 1941) although it was not reported in man until much later (Penfield and Rasmussen, 1950). Woolsey and Fairman (1946) found SII in a number of primates and subprimates and hypothesized that the second somatosensory map was an evolutionarily more primitive projection of the body surface that had been superceded by a newer projection to SI.

These classical experiments illustrated the regularity of the representation of the body surface on the cortical surface. With the exception of the hand-face transition, the representation appeared to follow a sequence dictated by the dermatomal sequence of spinal nerves (Bard, 1938). The maps were shown to be distorted in a characteristic manner so that the body parts with the greatest innervation density were given a much larger proportion of the cortical surface. In fact, the size of a cortical area devoted to a particular body part is thought to be proportional to, and dictated by, the innervation density of that part (Mountcastle, 1980).

The Cortical Column and Modality Specificity In 1957, Mountcastle recorded from 685 single units in areas $3 \mathrm{a}, 3 \mathrm{~b}, 1$, and 2 of cat somatosensory cortex. When electrodes were inserted perpendicular to the surface, all neurons encountered were of one modality and had overlapping receptive fields. When vertically-oriented electrode penetrations were not exactly perpendicular to the cortex, abrupt shifts in the nature of the adequate stimulus were observed. As the electrode advanced, regions driven by cutaneous stimuli gave way to regions driven by stimulation of deep structures or conversely responses driven by deep stimulation changed to responses best driven by cutaneous stimuli during the electrode trajectory. From this data he 

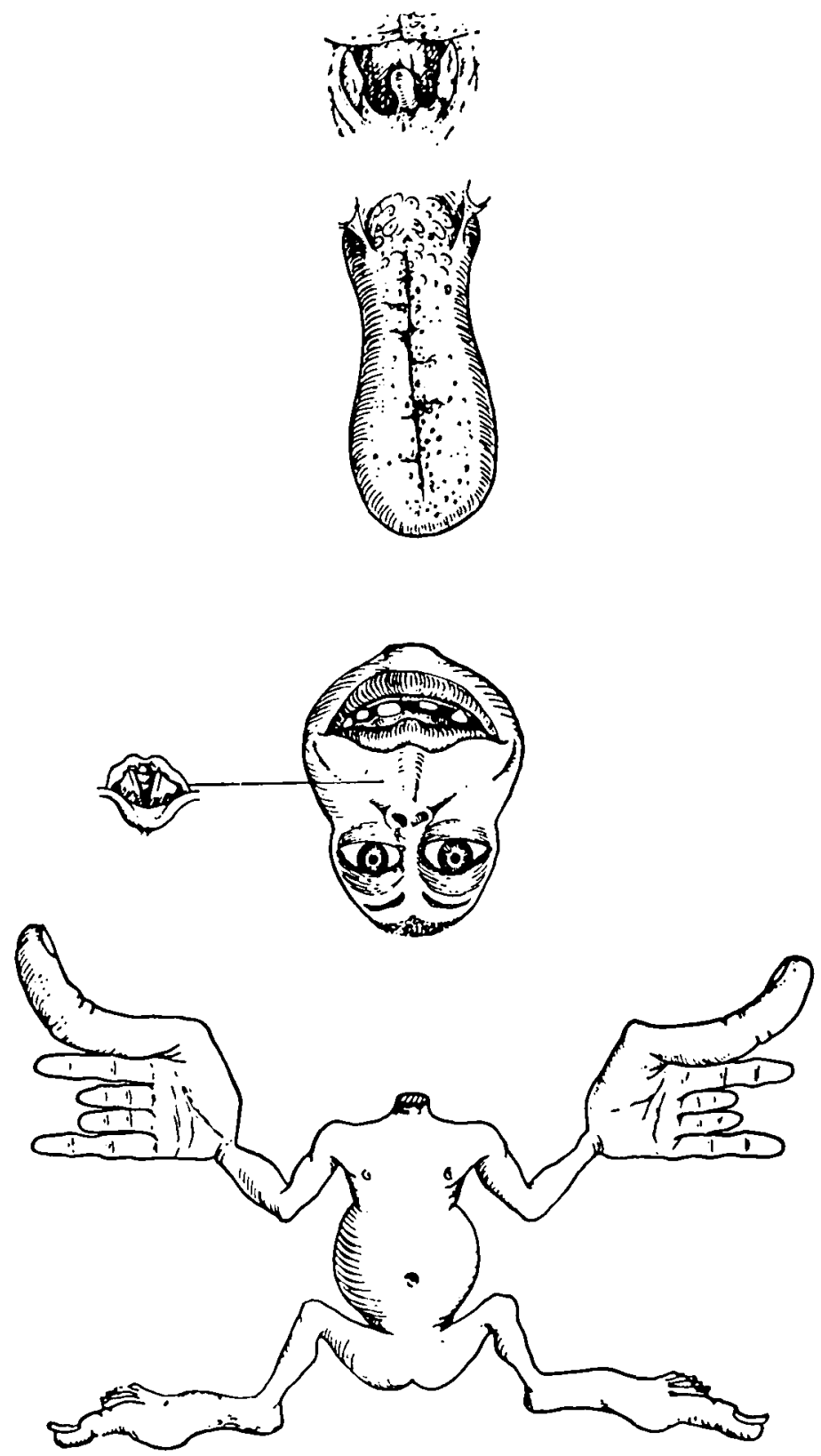

Figure 1 - (Reproduced with permission from Penfield and Boldrey, 1937) The single map of the body surface called the homunculus extending over the entire primary somatosensory cortex. The map is bilateral because one side is meant to represent the motor cortex and the other the sensory cortex.

formulated an hypothesis stating that the somatosensory cortex contained a mosaic of functional units consisting of vertical columns of neurons serving (i) one point on the body and (ii) one class of sensory receptors. The proportion of deep columns were said to be greater in the regions of SI caudal to area 3 while the proportion of cutaneous responses were greatest in the center of the somatosensory cortex. Subsequent to these experiments, cortical columns have been studied by numerous workers (Welt et al, 1967; Levitt and
Levitt, 1968; Dreyer et al, 1975) confirming the existence of functionally homogenous regions separated by boundaries where the function and receptive field change abruptly. Comparable functional units were reported in the visual cortex (Hubel and Wiesel, 1962) soon after their description in the somatosensory cortex and equivalent, vertically-arranged functional units were reported in the auditory cortex (Hind et al., 1960).

Modality Specificity of Cortical Neurons Included in the columnar hypothesis, although not stated explicitly, was the principle of modality specificity: That is, despite the multiple opportunities for the convergence of several classes of sensory receptors onto one cortical neuron, the neurons within one vertically-oriented region of primary somatosensory cortex, when activated by natural stimuli, appeared to receive excitatory inputs from only one class of receptors while adjacent areas were best activated by other classes. The modality classification employed by Mountcastle (1957) included hair, pressure, deep, and joint responses. Several examples of modality-specific neurons for each of these classes were presented in the early publications from his laboratory but no evidence of neurons activated by more than one class. (Mountcastle, 1957; Powell and Mountcastle, 1959; Mountcastle and Powell, 1959.) Neurons activated principally by one class of afferent input have now been reported at each level of the neuraxis, including submodality-specific neurons activated by cutaneous slowly adapting receptors, cutaneous rapidly adapting receptors, muscle spindle afferents, joint afferents and afferent fibers from pacinian corpuscles (Dykes, 1978). Neurons activated specifically by noxious stimuli, warm stimuli and cold stimuli have been identified in the spinal cord and thalamus (cf Willis and Coggeshall, 1978). So far the cortical projection of modality specific neurons of these latter classes has eluded the microelectrode.

These three concepts; the maps, the columns, and the modality specificity of somesthetic neurons are major parts of the foundation upon which our understanding of the functioning of the 
TABLE 1 -

Peripheral afferent nerve fibers in primates and their roles in sensation*

\begin{tabular}{|c|c|c|c|c|}
\hline $\begin{array}{l}\text { Type } \\
\text { of skin }\end{array}$ & $\begin{array}{l}\text { Fiber class, size, and } \\
\text { conduction velocity }\end{array}$ & $\begin{array}{l}\text { Peripheral } \\
\text { terminatlon }\end{array}$ & $\begin{array}{l}\text { Differential sensitivity } \\
\text { and adaptive property } \dagger\end{array}$ & Sensory function \\
\hline \multirow[t]{7}{*}{ Glabrous } & \multirow[t]{3}{*}{$\begin{array}{l}\text { A-beta, } * 6-12 \mu \\
35-75 \mathrm{~m} / \mathrm{sec}\end{array}$} & Merkel's cells & SA mechanoreceptors & $\begin{array}{l}\text { Velocity and position detectors; } \\
\text { scnse of touch-pressure }\end{array}$ \\
\hline & & $\begin{array}{l}\text { Meissner's cor- } \\
\text { puscles }\end{array}$ & QA mechanoreceptors & $\begin{array}{l}\text { Velocity and perhaps instanta- } \\
\text { neous position; sense of con- } \\
\text { tact and flutter; best at } 30-40 \\
\mathrm{~Hz}\end{array}$ \\
\hline & & Pacinian corpuscles & QA mechanoreceptors & $\begin{array}{l}\text { Velocity and perhaps higher de- } \\
\text { rivatives of position; sense of } \\
\text { contact and vibration; best at } \\
250-300 \mathrm{~Hz}\end{array}$ \\
\hline & \multirow{2}{*}{$\begin{array}{l}\text { A-delta, } 1-5 \mu, 5-30 \\
\mathrm{~m} / \mathrm{sec}\end{array}$} & Bare nerve endings & SA thermoreceptors & Sense of cooling \\
\hline & & Bare nerve endings & SA nociceptors & $\begin{array}{l}\text { Sense of pricking pain and, at } \\
\text { low frequencies, tickle }\end{array}$ \\
\hline & \multirow{2}{*}{$\begin{array}{l}\text { C fibers, } 0.2-1.5 \mu \\
0.5 .2 \mathrm{~m} / \mathrm{sec}\end{array}$} & Bare nerve endings & SA thermoreceptors & Sense of warming \\
\hline & & Bare nerve endings & SA nociceptors & $\begin{array}{l}\text { Sense of burning pain and, at low } \\
\text { frequencies. itch }\end{array}$ \\
\hline \multirow[t]{11}{*}{ Hairy } & \multirow[t]{5}{*}{$\begin{array}{c}\text { A-beta,* } 6-12 \mu \\
35-75 \mathrm{~m} / \mathrm{sec}\end{array}$} & $\begin{array}{l}\text { Hair follicle ap- } \\
\text { paratus }\end{array}$ & QA mechanoreceptor & $\begin{array}{l}\text { Velocity detectors: sense of con- } \\
\text { !act and flutter; best at } 30-40 \\
\mathrm{~Hz}\end{array}$ \\
\hline & & $\begin{array}{l}\text { Bare nerve endings, } \\
\text { "field" recep- } \\
\text { tors }\end{array}$ & QA mechanoreceptor & $\begin{array}{l}\text { Velocity detectors: sense of con- } \\
\text { tact }\end{array}$ \\
\hline & & $\begin{array}{l}\text { Pinkus domes, } \\
\text { Merkel cells }\end{array}$ & $\begin{array}{l}\text { SA " "type I" mech- } \\
\text { anoreceptor }\end{array}$ & $\begin{array}{l}\text { Stimulation in human elicits } \\
\text { no sensation }\end{array}$ \\
\hline & & Ruffini organs & $\begin{array}{l}\text { SA "type II" mech- } \\
\text { anoreceptor }\end{array}$ & $\begin{array}{l}\text { Velocity and position detectors; } \\
\text { sense of touch-pressure }\end{array}$ \\
\hline & & $\begin{array}{l}\text { Pacinian cor- } \\
\text { puscles }\end{array}$ & QA mechanoreceptor & $\begin{array}{l}\text { Velocity and perhaps higher de- } \\
\text { rivatives of position; sense of } \\
\text { vibration; best at } 250-300 \mathrm{~Hz}\end{array}$ \\
\hline & \multirow{3}{*}{$\begin{array}{l}\text { A-delta, } 1-5 \mu \\
5.30 \mathrm{~m} / \mathrm{sec}\end{array}$} & Bare nerve endings & QA mechanoreceptor & Velocity; sense of contact \\
\hline & & Bare nerve endings & SA thermoreceptor & Sense of cooling \\
\hline & & Bare nerve endings & SA nociceptors & $\begin{array}{l}\text { Sense of pricking pain and, } \\
\text { at low frequencies, tickle }\end{array}$ \\
\hline & \multirow{3}{*}{$\begin{array}{l}\mathrm{C} \text { fibers, } 0.2-1.5 \mu \\
0.5-2 \mathrm{~m} / \mathrm{sec}\end{array}$} & Bare nerve endings & SA thermoreceptors & Sense of warming \\
\hline & & Bare nerve endings & SA nociceptors & $\begin{array}{l}\text { Sense of hurning pain and, } \\
\text { at low frequencies, itch }\end{array}$ \\
\hline & & Bare nerve endings & SA mechanoreceptors & $\begin{array}{l}\text { Occur rarely in monkey skin and } \\
\text { not present in human skin }\end{array}$ \\
\hline
\end{tabular}

\footnotetext{
*In earlier classifications these fibers were labeled A-alpha. They are, however, similar in size to the second group of afferent fibers in muscle nerves. Thus they are termed A-beta fibers here, which allows a correlation between the systems of classification as follows: group I = A-alpha; group II = A-beta; group III = A-delta; and group IV = C fibers.

$\dagger \mathrm{SA}=$ slowly adapting; $\mathrm{QA}=$ quickly adapting. ${ }^{*}$ From Mountcastle, Vernon B: Sensory receptors and neural encoding: introduction to sensory processes. In Mountcastle, Vernon B, editor: Medical Physiology ed. 14, St. Louis, 1980, C.V. Mosby Co.
} 
somatosensory system rests. Presently, all of these ideas are undergoing a rapid evolution. The rest of this article is an attempt to restate each idea in a modern form following a brief comment about the techniques and discoveries that prepared the way for these changes.

\section{CONCEPTUAL AND TECHNICAL PRECONDITIONS FOR A MODERN PICTURE OF SOMATOSENSORY CORTEX \\ Specificity of Sensory Receptors} Over the last 20 years, anatomists and physiologists have argued about classifications of cutaneous sensory receptors (these arguments are reviewed by Sinclair, 1967). One school, believing that the pattern of neural activity presented to the central nervous system was the most important aspect of sensation, argued that sensory receptors are found in a diversity of sizes and shapes and respond to a diversity of stimuli. This theory held that different sensory experiences must arise from the different patterns of neural activity set up in a heterogeneous receptor population. To support this theory, evidence was marshalled suggesting that distinct classes of receptors did not exist. Instead, the theory said, light tactile stimuli activated only a few receptors, and the sensations elicited by thermal stimuli, for example, were differentiated from tactile stimuli by provoking another pattern in this same receptor population. Then, with the addition of a few unmyelinated fiber terminals, this new pattern allowed noxious stimuli to be recognized simply as the intense activation of all large and small fibres. A form of this idea still exists today as the gate control theory of pain.

The other school of thought, believing in specificity, held that there were specific classes of receptors each selectively activated by a different class of stimuli and each giving rise to a different sensation. Thus, tactile stimuli were said to activate encapsulated receptors, thermal stimuli to activate one class of free nerve endings, and noxious stimuli to activate another class of free nerve endings. Without question, the weight of evidence now favors this specificity theory. There is physiological and anatomical evidence for specific thermoreceptors, nociceptors, joint afferents, pressure and vibration detectors (for reviews: cf., Dykes, 1977; Mountcastle, 1980).

As indicated above, during the last two decades, neurons responding selectively to only one of these specific receptor classes have been located at each level of the somatosensory pathway. Thus, in at least some cases, specific information about modality and submodality is encoded by the receptors and is preserved at successive synapses in the central somesthetic pathways. Mountcastle (1957) has been shown not only to be correct about modality specificity, but the specificity of synaptic input is even greater than he originally proposed. Perhaps it is valid even to the point that for each class of sensory receptors there is a unique class of afferent neurons and a particular sensory experience. Table I summarizes the major classes of sensory receptors found in the skin of man and other primates and lists their putative sensory correlates (Mountcastle, 1980).

Electrophysiological Mapping Techniques Another prerequisite for our modern concepts is the existence of new investigative tools that have provided novel information about the somatosensory pathways. The classical maps of the cortex were obtained with evoked potentials recorded from surface electrodes placed at successive points one $\mathrm{mm}$ or more apart. In man and monkeys, generally only three or four points were recorded across the entire width of the postcentral gyrus. Welker (1971) introduced the use of low impedance microelectrodes to record multiunit data from points much closer together within the somatosensory maps and thereby provided the means to obtain higher resolution information about the organization of these regions. The newer maps of both the cortical and subcortical structures in the somatosensory pathways have been obtained with multiunit recordings taken at intervals of 50 to $300 \mu \mathrm{m}$. This method provides more than an order of magnitude improvement in spatial resolution.
Anatomical Tracing Techniques The study of neuroanatomy has been revolutionized by the use of horseradish peroxidase and radio-labelled amino acids to trace neuronal connections. For the somatosensory pathways, these techniques have allowed functionally identified regions to be labelled so that details of their connections to other areas can be defined. Particularly in this context, the origin of the afferent inputs to a specific region can be ascertained with a precision and detail never before possible, thereby allowing inferences about the detailed spatial organization of the various inputs to those regions so identified.

\section{CURRENT VIEWS}

Modern Maps - Multiple Homunculi Turning now to the newer ways to look at the somatosensory system, a major step was taken by Paul et al (1972) who used the low-impedance microelectrode technique to discover that the postcentral gyrus of primates contained two separate and complete maps of the hand within what was originally thought of as the single homunculus. This same microelectrode mapping technique was used effectively by Sur et al (1978) to provide extremely high resolution maps of primary somatosensory cortex of the grey squirrel. Then Kaas, Merzenich and their colleagues, mapped the entire somatosensory cortex of several different species of primates showing in each case that there was at least a double representation of the body on the postcentral gyrus (Merzenich et al, 1978; Kaas et al, 1979; Sur et al, 1980; Nelson et al, 1980). One body map was located in cytoarchitectonic area $3 \mathrm{~b}$ and the other in area 1 (Fig. 2). Thus, primary somatosensory cortex of the primate contains at least two complete homunculi. In addition there is some evidence for additional representations located in adjacent regions (Merzenich and Kaas, 1980). This experiment has not been performed in man but the likelihood that a dual map exists in areas $3 \mathrm{~b}$ and 1 of man is overwhelming.

If the number of maps of the body surface reported to exist in the somatosensory cortex are enumerated, the two found in SI can be added to the 

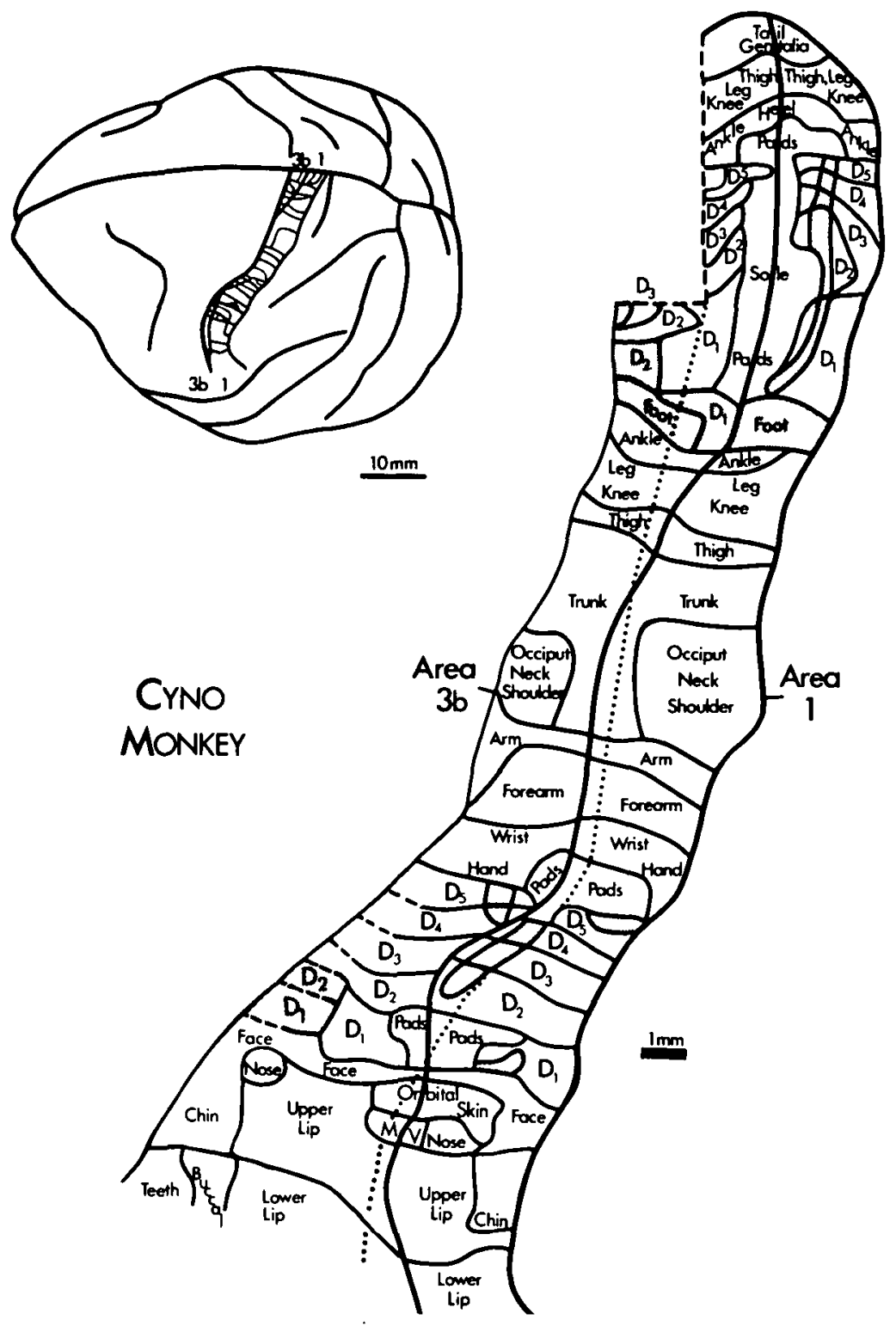

Figure 2 - (Reproduced with permission from Nelson et al, 1980) Two maps in primary somatosensory cortex of the cynomdogous monkey (Macaca fascicularis) as obtained by the fine grain microelectrode mapping technique of Welker (1971).

map in SII and the more elusive map in SIII reported only rarely (Tasker, 1960; Darian-Smith et al, 1966; Tanji et al, 1978). In addition, there is another representation of the body in area $3 \mathrm{a}$ between area $3 \mathrm{~b}$ and motor cortex (Oscarsson and Rosen, 1966; Dykes et al, 1980b), making a total of five that are well-documented. Merzenich and Kaas (1980) suggest that there may be as many as ten; clearly the somatosensory cortex contains a multiplicity of body representations.

This observation prompts the question of causation - why do multiple maps exist? That each is a successive evolutionary step in the development of the neocortex is no longer a satisfactory answer. One can obtain another answer by carefully recording the nature of the adequate stimulus required to activate the neurons in each map. From such data it becomes apparent that each map is best activated by a different class of somatic stimuli. Further, these classes of stimuli suggest that the predominant input to each map is one particular class of sensory receptors. Tests were designed to differentially activate rapidly adapting cutaneous receptors, slowly adapting cutaneous receptors, pacinian corpuscles and muscle spindles (Dykes et al, 1980b), and were used to identify the receptor classes which best activated cortical neurons. When these tests were applied repeatedly to neurons observed at successive loci within the cat somatosensory cortex, the response classes were not randomly distributed, but were segregated into specific nuclear regions. These regions appeared to contain a complete map of the body. Thus each map consisted of a segregated population of neurons serving a specific submodality or class of sensory receptors.

For example, as has been argued for some time, recordings in area $3 \mathrm{a}$ showed that this particular cortical area received input only from deep structures, (Oscarsson and Rosen, 1966) probably muscle spindles, and that when the exploring electrode crossed the cytoarchitectonic boundary between areas $3 a$ and $3 b$ the responses abruptly changed so that the neurons were optimally driven by stimuli which activated cutaneous receptors (Fig. 3) (Rasmusson et al, 1979).

Once the electrode crossed into area $3 \mathrm{~b}$ and the responses were driven by cutaneous stimuli, they never reverted to activation by stimuli applied to deep structures. The transition from deep to cutaneous responses was abrupt and complete; seldom were mixtures of cutaneous and deep inputs observed.

By making many penetrations in the cortex and recording the receptive fields encountered at each cortical locus, a complete representation of the deep inputs (muscle spindles) was found in area 3a and appeared to be co-extensive with this cytoarchitectonic area in cats (Dykes et al, 1980b). Merzenich, Kaas and their colleagues have shown that there are complete 
cutaneous maps in cytoarchitectonic regions of $3 \mathrm{~b}$ and 1 of the owl monkey (Merzenich et al, 1978) and macaque monkey, (Nelson et al, 1980). In cats, by giving careful attention to the submodality of the cutaneous responses, (ie., whether neurons are best activated by cutaneous slowly adapting or cutaneous rapidly adapting inputs) it is possible to show that even within area $3 \mathrm{~b}$, there are two maps. These two response classes are segregated into distinct bands running mediolaterally within area 3b (Dykes et al, 1980b).

Such an analysis can be extended to other receptor classes. It is possible to readily identify inputs from pacinian corpuscles because they are sensitive to very high frequency vibrations and have large receptive fields. Thus, it is relatively straightforward to ask where their inputs terminate in the sensory cortex. Traditionally, input from pacinian afferents has been difficult to find in SI. Mountcastle et al (1969) found that only $4 \%$ of 1099 units could be activated by stimuli thought to selectively drive pacinian corpuscles, and even those cortical neurons so activated could not be cyclically entrained. The reason for this is now apparent; pacinian input is preferentially directed towards SII (Bennett et al, 1980, Ferrington and Rowe, 1980) and it now appears likely that SII contains a map of the body devoted to input from pacinian afferent fibres. SII also has been implicated as a recipient of other classes of sensory input (Bennett et al, 1980) and eventually may be shown to contain several other representations in addition to the pacinian map.

The functions of those portions of primary somatosensory cortex identified cytoarchitectonicaly as areas 1 and 2 are still poorly characterized. However, from the limited data available, they seem to contain additional maps of the body surface. Merzenich et al (1978) have drawn a detailed and complete map for area 1 in monkey and a partial map in area 2 . Based upon only a few penetrations, Dykes et al (1980b) suggested that area 1 in cats also contains a body map. The penetrations passing through area 1 generally provided cutaneous rapidly adapting responses but on some occa-

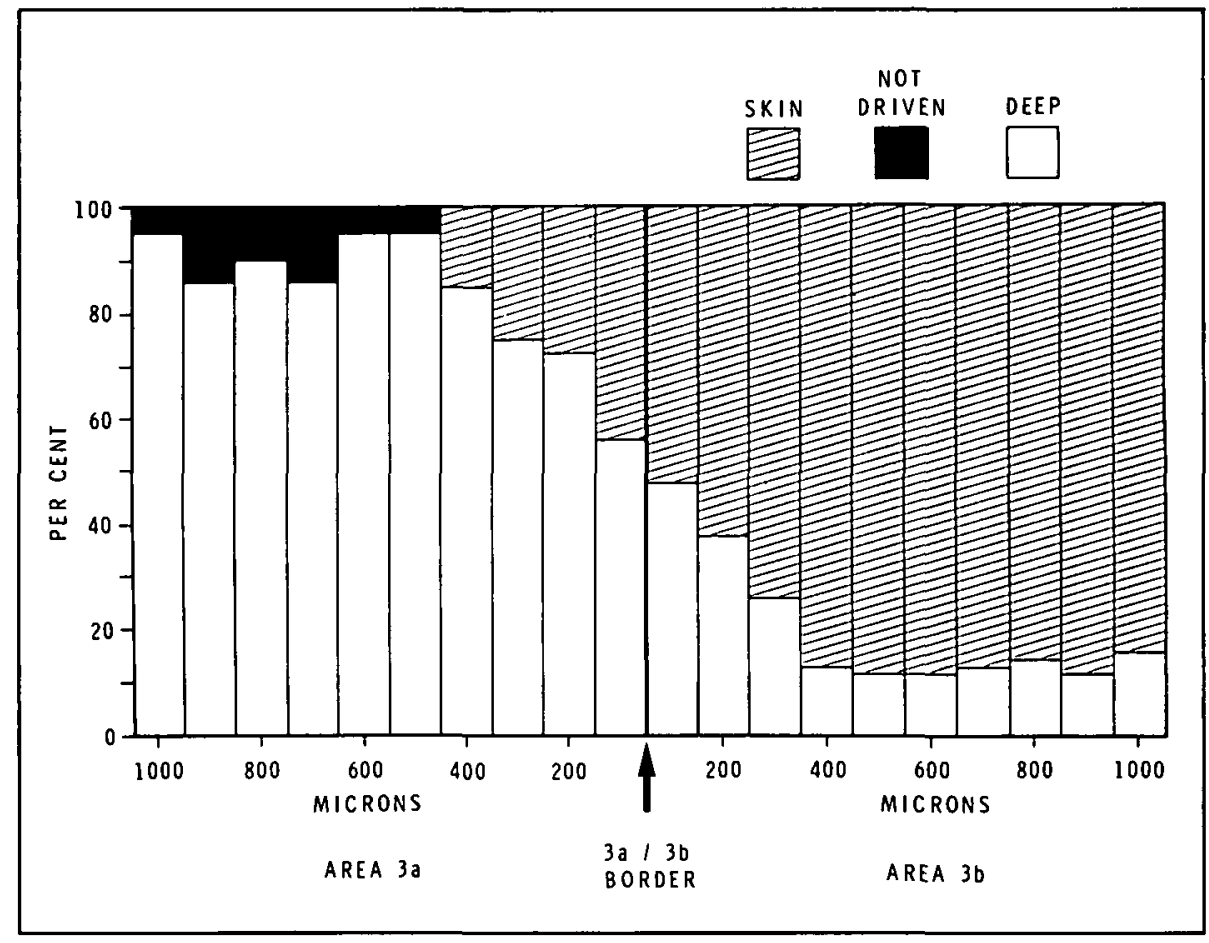

Figure 3 - (Reproduced with permission from Rasmusson et al, 1979) Percentage of deep, skin and non-drivable sites encountered in progressive $100 \mathrm{um}$ steps during electrode trajectories that crossed the area $3 \mathrm{a} / \mathrm{area} 3 \mathrm{~b}$ border. $\mathrm{n}<30$.

sions deep responses were encountered. Mountcastle (1957) and Powell and Mountcastle (1959) reported an increasing probability of encountering regions receiving input from deep structures when electrodes were placed at progressively posterior regions in areas 1 and 2 , until in the most posterior region only $10 \%$ of the neurons were activated by cutaneous receptors. Thus, it is not yet clear that either areas 1 or 2 serve only one modality, and these regions must be explored further.

Nevertheless, major portions of somatosensory cortex consist of a series of body representations wherein each map is restricted to a single cytoarchitectonic area and in those areas studied most carefully, each serves a particular class of sensory receptors. Such an arrangement suggests that the multiple maps exist so that there will be a distinct cortical region to serve each of several discrete classes of somatic receptors.

Multiple maps and the cortical column Since the cortical column is recognized electrophysiologically by the nature of the stimulus adequate to excite the constituent neurons, modality-specific maps, each restricted to one cytoarchitectonic zone, must modify the concept of the cortical column. Mountcastle (1957) and Powell and Mountcastle (1959) recognized a cortical column by the changes that occurred at its boundary. Either a change in submodality or a shift in the receptive field locus signalled the border. It is apparent now that these changes occur predominantly at the edges of each map (Rasmusson et al, 1979; Dykes et al, 1980b; Dykes and Gabor, 1980; 1981; Sretavan and. Dykes, 1980) and consequently that the functional criteria for recognizing the edge of a cortical column correspond to the transition region between two distinct maps in the somatosensory cortex. Thus, a change in the nature of the adequate stimulus occurs once at the $3 a-3 b$ boundary and generally again only once within area $3 \mathrm{~b}$ when the slowly adapting to rapidly-adapting transition occurs.

When long slanting penetrations are oriented to run along the mediolateral length of the somatosensory cortex (in a direction equivalent to running along the mediolateral length of the postcentral gyrus), then the receptive field sequences are a smooth gradient of 


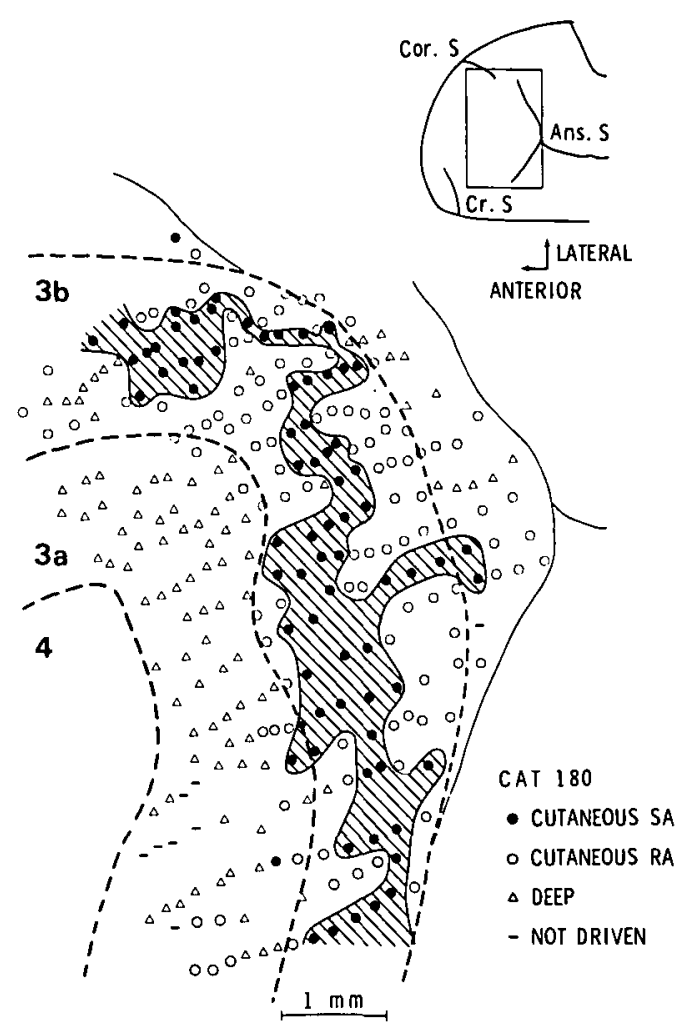

Figure 4 - (Modified and reproduced with permission from Dykes et al, 1980) Surface view of somatosensory cortex in an experiment during which several hundred vertical penetrations were made. Modality and submodality data are shown by different symbols. Note that with few exceptions, area $3 \mathrm{a}$ is activated by inputs from deep structures and area $3 \mathrm{~b}$ is activated by cutaneous stimuli. Within area $3 \mathrm{~b}$ the cutaneous responses are segregated so that the slowly adapting responses form a wavy band stretching along its mediolateral length.

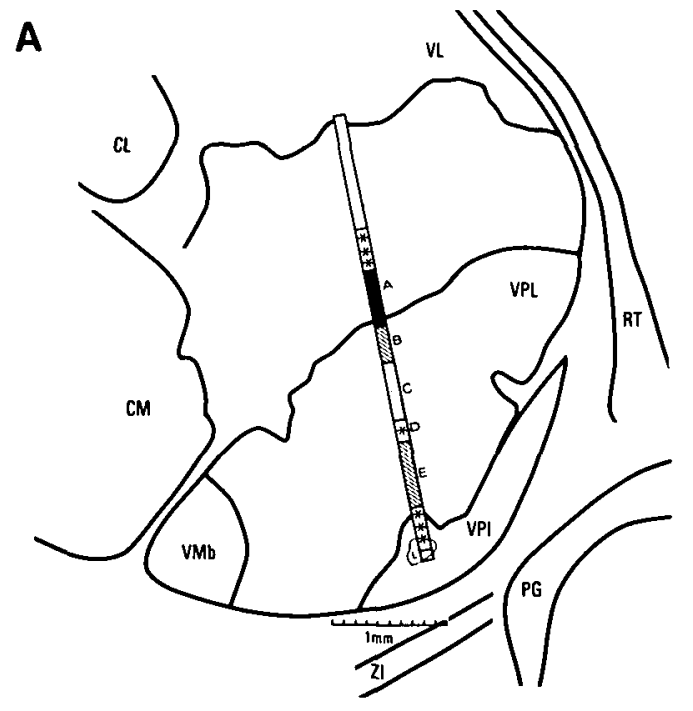

Figure 5a - (Reproduced with permission from Dykes et al, 1981) Frontal section of the thalamus and corresponding electrophysiological data. The major nuclear regions are outlined with heavy dotted lines and identified with labels (Nuclei: $V L=$ ventrolateral, $C L=$ centralis lateralis, $\mathrm{CM}=$ centralis medialis, $\mathrm{VPL}=$ ventralis posterolateralis, $\mathrm{RT}=$ reticularis, $\mathrm{VPI}=$ ventral posterior inferior, $P G=$ pregeniculate). The electrode track is coded according to the responses encountered and terminates in a lesion. $(A=$ deep, $B=$ cutaneous rapidly adapting, $C=$ cutaneous slowly adapting, $\mathrm{D}=$ tap, $\mathrm{E}=$ cutaneous rapidly adapting). gradually shifting, partly overlapping regions on the body, and in this direction receptive field jumps that might signal the boundary of the cortical column are seldom encountered. These observations suggest that empiricallydemonstrable cortical columns are long narrow bands running the length of the cytoarchitectonic bands in SI and are equivalent to the individual functional maps which exist within each cytoarchitectonic region (Dykes and Gabor, 1981).

The concept of modality-specific neurons activated by a particular subset of sensory receptors as originally documented by Mountcastle (1957) has been strengthened by this modern picture of somatosensory cortex. However, instead of being a mosaic of modality-specific cylinders, the cortex is seen to be divided into mediolateral modality-specific bands correlated with cytoarchitecture (Fig. 4). In cats, the width of these bands having a common function vary from 0.5 to $1.5 \mathrm{~mm}$ wide and all neurons in these areas seem to be activated by the same type of input (Dykes and Gabor, 1980; 1981). The degree of modality-specificity characteristic of a particular region is not yet clear. Whether convergence is limited very strictly only to one class of afferents or whether there is a major and a minor input to a given zone are questions that will require additional experiments. Certainly these rules of submodality segregation must be relaxed at some point in order to facilitate the integration seen in interneurons and to organize the appropriate corticofugal signals. The virtue of such a parallel, submodality-specific relay system is that it allows afferent signals to be relayed centrally without loss of information about the nature of the adequate stimulus, and simultaneously allows processing of the signal to enhance spatial and temporal contrast before it is integrated with other afferent signals. These considerations, in turn, lead to the question of how the subcortical synaptic regions are organized so that the submodality of the afferent signal is so well preserved during its relay to the cortex.

Subcortical Organization of Receptor-Specific Relay Regions Data for subcortical regions equivalent to that 
presented above for the cortical areas, have been obtained only recently, and with the exception of two experiments in primates (Friedman and Jones, 1981; Dykes et al, 1981) all of the data have been derived from studies of cats. However, the cat cortex has proven to be an excellent predictor of the organization of primate cortex and there is little reason to believe that subcortical regions will not follow the same pattern in monkeys and man. Consequently, the following data in cats will be presented with the assumption that in the future an equivalent organization will be found in primates.

Functional Organization of the Somatosensory Thalamus The ventroposterior (VP) nucleus of the thalamus can be divided into five parts. These are the inferior, medial, lateral, oral and superior divisions, or VPI, VPM, VPL, VPO and VPS respectively (Dykes et al, 1980a). Using electrophysiological mapping techniques combined with injections of HRP and radio-labelled proteins Dykes et al (1980a) confirmed the observations of Oscarsson and Rosen (1966) that VPO receives input from muscle spindles and projects to area $3 \mathrm{a}$ of the somatosensory cortex. Similar observations concerning VPLc pars oralis of monkeys (VPO of cats) (Dykes et al, 1981; Friedman and Jones, 1981) suggest that this region also serves muscle spindles in the primate. In the monkey, the cortical projection of VPLc pars oralis is less well-defined and may project to several other areas as well as area 3a. (Jones and Porter, 1980). The VPL portion of the thalamus receives input from cutaneous receptors and appears to be divided into discrete regions devoted to slowly adapting and rapidly adapting inputs in the same way area $3 \mathrm{~b}$ is divided (Fig. 5) (Dykes et al, 1981). Beneath the VPL is the VPI nucleus. Electrophysiological recordings within VPI indicate that input from pacinian corpuscles terminates there. HRP injections into SII showed that the VPI nucleus projects to SII (Herron, 1981; Herron and Dykes, 1981) where the map of pacinian input is situated. Thus, VPI is a relay nucleus for pacinian corpuscles.

A posterior thalamic region just dorsal to VPL is a rostral extension of the

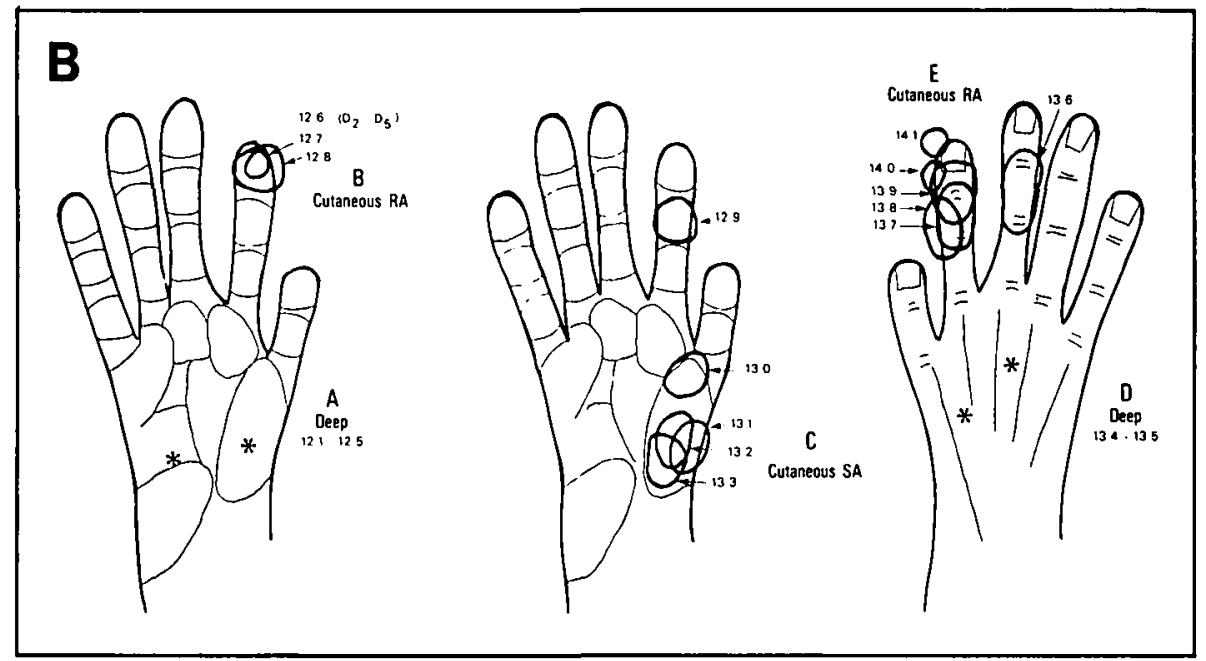

Figure $5 b$ - Loci of successively encountered receptive fields observed during the trajectory shown in part A. Letters A through E correspond to the regions marked in part A. (Reproduced with permission.)

posterior group of thalamic nuclei named nucleus posterior oralis medialis (POm). This region projects to area $5 \mathrm{a}$ (the third somatic sensory area, SIII) (Tanji et al, 1978). Recently a series of experiments repeating some of the observations of Poggio and Mountcastle $(1960)$ showed that there is a subregion of Pom which receives input from cutaneous rapidly adapting neurons having moderately high thresholds and characteristically large receptive fields. These neurons appear to receive their inputs from a set of spinal neurons with similar functional properties located in the lateral cervical nucleus (da Costa et al, 1981). The inference from these observations is that there are a number of discrete submodality-specific nuclear regions in the somatosensory thalamus. Each projects preferentially to a specific cortical region and each probably conveys information from one or a few selected classes of cutaneous sensory receptors. Obviously the principles of organization of the VP thalamus appear very similar to those found in the somatosensory cortex where specific regions each serve a specific receptor class.

Organization of the Dorsal Column Nuclei $(D C N)$ The same combined anatomical and electrophysiological analysis has been extended to the DCN to show that here again discrete nuclear volumes serve specific classes of receptors and project to specific thalamic relay nuclei. The external cuneate nucleus and its extension under the main cuneate nucleus have been known for some time to serve muscle spindles (Rosen and Sjolund, 1973) and to project preferentially to the muscle spindle region of the thalamus, VPO (Oscarsson, 1966; Dykes et al, 1980a). The microelectrode maps of the central regions of the cuneate and gracile nuclei show that this region receives only cutaneous inputs and that these inputs are grouped into discrete regions serving cutaneous slowly adapting receptors and other regions serving cutaneous rapidly adapting receptors. The spatial arrangement of these segregated regions within the central core of the DCN is not clear but all major body parts have been found to be represented in both parts. The data support the hypothesis that at least two complete maps of the body exist here - one serving slowly adapting receptors and one serving rapidly adapting receptors.

In the caudal portion of the cuneate and gracile nuclei is a cytoarchitectonically-distinct region wherein cells can be activated by stimuli that selectively activate pacinian corpuscles. This region appears to receive input from pacinian corpuscles located in all parts of the body except the face and thus to contain a representation of the body exclusive of the face. Injections of HRP into the VPI nucleus of the thalamus label cells in this caudal part of the DCN demonstrating that this region projects to the thalamic area which receives pacinian input. 


\section{SUMMARY}

At each level of the neuraxis there exist segregated nuclear regions activated selectively by a specific class of sensory receptors. Each of the subcortical regions projects preferentially to a selected region at the next higher level of the somatosensory pathway where again a particular nuclear region is activated by that same specific class of receptors (Fig. 6).

This arrangement can be described as a parallel relay and processing of somatic sensory information. Parallel processing also exists in the visual system (Stone et al, 1979) where it appears to follow very similar rules of organization. The virtues of this conceptualization in the somatosensory system are: (i) It provides a partial explanation of how modality-specific input can be relayed to the somatosensory cortex despite the obvious divergence and the convergence which occurs at each synaptic level; (ii) it suggests that the multiple representations of the body located in the somatosensory cortex are there so that each may serve a separate class of inputs; (iii) it predicts where the transition points of the cortical columns will be found; and finally (iv) it suggests a new shape for those cortical units Mountcastle (1957) called columns.

\section{ACKNOWLEDGEMENTS}

This work was supported by the Medical Research Council of Canada. I am indebted to Mr. Maurice Murphy, graphiste, Mr. Charles Hodge, photographer, and Mrs. Genevieve Holding, typist for their constant support and cooperation.

\section{REFERENCES}

ADRIAN, E.D. (1941) Double representation of the feet in the sensory cortex of the cat. $J$. Physiol. 98: 16p-18p.

BARD, P. (1938) Studies on the cortical representation of somatic sensitivity. Bull. N.Y. Acad. Med. 14: 585-607.

BENNETT, R.E., FERRINGTON, D.G. and ROWE, M. (1980) Tactile neuron classes within second somatosensory area (SII) of the cat cerebral cortex. J. Neurophysiol. 43: 292-309.

da COSTA, D.C.N., METHERATE, R.S., HERRON, P. and DYKES, R.W. (1981) A thalamic terminus for the lateral cervical nucleus. Soc. Neurosci. Abstr. 7.

DARIAN-SMITH, I., ISBISTER, J., MOK, H. and YOKOTA, T. (1966) Somatic sensory cortical projection areas excited by tactile stimulation of the cat: a triple representation.J. Physiol. 182: 671-689.

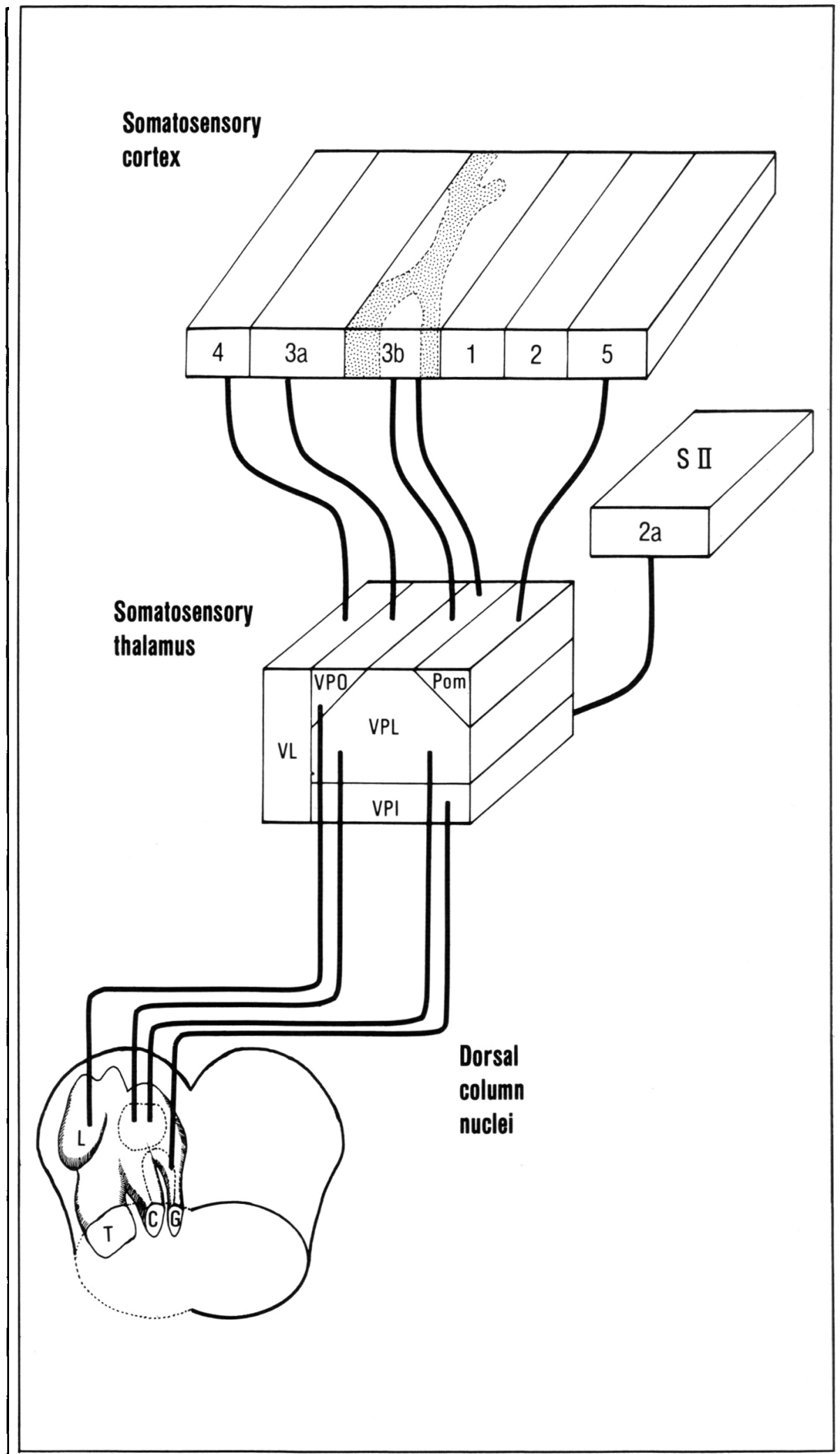

Figure 6 - Summary of modality specific connections in the dorsal column-medial lemniscal system. Specific classes of sensory receptors converge upon discrete regions of the dorsal column nuclei. These nuclear regions relay their receptor-specific information to separate nuclear regions in the somatosensory thalamus which, in turn, project to specific cortical areas. This arrangement gives rise to multiple cortical representations each of which is preferentially activated by a different class of somatic sensory information. 
DREYER, D.A., LOE, P.R., METZ, C.B. and WHITSEL, B.L. (1975) Representation of the head and face in the postcentral gyrus of the Macaque.J. Neurophysiol. 38: 714-733.

DYKES, R.W. (1977) Sensory receptors. ch 9: pp. 320-333. In: Reconstructive Microsurgery, R. Daniel and J. Terzis. Little, Brown \& Co. Boston, Mass.

DYKES, R.W. (1978) The anatomy and physiology of the somatic sensory cortical regions. Prog. Neurobiol. 10:33-88.

DYKES, R.W. and GABOR, A. (1980) Magnification factors and receptive field sequences in submodality-specific bands of cat SI cortex. (Abstr) Proc. Int. Union. Physiol. Sci. 14: 392 (Budapest).

DYKES, R.W. and GABOR, A. (1981) Magnification functions and receptive field sequences for submodality-specific bands in SI cortex of cats. J. Comp. Neurol. 202: 597-620.

DYKES, R.W., LIN, C.S. and REHMAN, N. (1980a) Thalamocortical projection nuclei for modality-specific regions of somatosensory cortex: demonstration of different projections for areas $3 \mathrm{a}$ and $3 \mathrm{~b}$ of the cat. The Physiologist 23: 73 .

DYKES, R.W., RASMUSSON, D.D. and HOELTZELL, P.B. (1980b) Organization of primary somatosensory cortex in the cat. J. Neurophysiol. 43: 1527-1546.

DYKES, R.W. and SRETAVAN, D. (1981) Submodality and its relationship to somatotopy in the forearm region of cat cortex. Neurosc. Soc. Abstr. 7: 834

DYKES, R.W., SUR, M., MERZENICH, M.M., KAAS, J.H. and NELSON, R.J. (1981) Regional segregation of neurons responding to quickly adapting, slowly adapting, deep and pacinian receptors within thalamic ventroposterior lateral and ventroposterior inferior nuclei in the squirrel monkey (Saimiri sciureus). Neurosci Vol. 6 : 1687-1692.

FERRINGTON, D.G. and ROWE, M. (1980) Differential contributions to coding of cutaneous vibratory information by cortical somatosensory areas I and II. J. Neurophysiol. 43: 310-331.

FRIEDMAN, D.P. and JONES, E.G. (1981) Thalamic input to areas $3 \mathrm{a}$ and 2 in monkeys. J. Neurophysiol. 45: 59-85.

HERRON, P. (1981) The connections of cortical somatosensory areas I and II with separate nuclei in the ventroposterior region of the thalamus in the raccoon. Neurosci. (In press).

HERRON, P. and DYKES, R.W. (1981) Connections of the ventroposterior inferior nucleus of the thalamus in cats. Soc. Neurosci. Abstr. 7: 396.

HIND, J.E., ROSE, J.E., DAVIES, P.W. WOOLSEY, C.N., BENJAMIN, R.M., WELKES, W.S., and THOMPSON, R.F. (1960) Unit activity in the auditory cortex.
In: Neural Mechanisms of the Auditory and Vestibular Systems, Thomas, Springfield.

HUBEL, D.H. and WIESEL, T.N. (1962) Receptive fields, binocular interaction and functional architecture in the cat's visual cortex. J. Physiol. 160: 106-154.

JONES, E.G. and PORTER, R. (1980) What is area 3a? Brain Res. Rev. 2: 1-43.

KAAS, J.H., NELSON, R.J., SUR, M., LIN, C.S. and MERZENICH, M. (1979) Multiple representations of the body within the primary somatosensory cortex of primates. Science 204: 521-523.

LEVITT, J. and LEVITT, M. (1968) Sensory hind-limb representation in the SMI cortex of the cat. A unit analysis. Expl. Neurol. 22: 259-275.

MERZENICH, M.M. and KAAS, J.H. (1980) Principles of organization of sensoryperceptual systems in mammals. In: Progress in Psychobiology and Physiological Psychology, N.Y. Academic press. Vol. 9, pp. 1-42, Ed. J.M. Sprague and A.N. Epstein.

MERZENICH, M.M., KAAS, J.H., SUR, M. and LIN, C.S. (1978) Double representation of the body surface within cytoarchitectonic areas $3 \mathrm{~b}$ and 1 in "SI" in the owl monkey. (Aotus trivirgatus). J. Comp. Neurol. 181: 41-74.

MOUNTCASTLE, V.B. (1957) Modality and topographic properties of single neurons of cat's somatic sensory cortex. J. Neurophysiol. 20: 408-434.

MOUNTCASTLE, V.B. (1980) Sensory receptors and neuronal encoding: introduction to sensory processes. pp. 327-347. ch. 11 In: Medical Physiology Vol. l. ed. V.B. Mountcastle. C.V. Mosby Co. St. Louis.

MOUNTCASTLE, V.B. and POWELL, T.P.S. (1959) Central nervous mechanisms subserving position sense and kinesthesia. John Hopkins Hosp. Bull. 105: 173-200.

MOUNTCASTLE, V.B., TALBOT, W.H., SAKATA, H. and HYVARINEN, J. (1969) Cortical neuronal mechanisms in fluttervibration studied in unanesthetized monkeys. Neuronal periodicity and frequency discrimination. J. Neurophysiol. 32: 452-484.

NELSON, R.J., SUR, M., FELLEMAN, D.J. and KAAS, J.H. (1980) The representations of the body surface in postcentral somatosensory cortex of Macaca fascicularis. $J$. Comp. Neurol. 192: 611-644.

OSCARSSON, O. (1966) The projection of Group I muscle afferents to the cat cerebral cortex. In: Nobel Symposium I: Muscle Afferents and Motor Control. pp. 307-316. Ed. R. Granit. Wiley, N.Y.

OSCARSSON, O. and ROSEN, I. (1966) Short latency projections to the cat's cerebral cortex from skin and muscle afferents in the contralateral forelimb. J. Physiol. 182: 164184.
PAUL, R.L., MERZENICH, M., and GOODMAN, H. (1972) Representation of slowly and rapidly adapting cutaneous mechanoreceptors of the hand in Brodman's areas 3 and 1 of Macaca mulatta. Brain Res. 36: 229-249.

PENFIELD, W. and BOULDREY, E. (1937) Somatic motor and sensory representation in the cerebral cortex of man as studied by electrical stimulation. Brain. 60: 389-443.

PENFIELD, W. and RASMUSSEN, T. (1950) The cerebral cortex of man. pp. 248. Macmillan, N.Y.

PENFIELD, W. and JASPER, H. (1954) Epilepsy and the functional anatomy of the human brain. In: Functional Localization in the Cerebral Cortex. pp. 41-155. Little, Brown and Co., Boston, Mass.

POGGIO, G.F. and MOUNTCASTLE, V.B. (1960) A study of the functional contributions of the lemniscal and spinothalamic systems to somatic sensibility. Central nervous mechanisms in pain. Johns Hopkins Hosp. Bull. 106: 266-316.

POWELL, T.P.S. and MOUNTCASTLE, V.B. (1959) Some aspects of the functional organization of the cortex of the postcentral gyrus of the monkey: a correlation of findings obtained in a single unit analysis with cytoarchitecture. Johns Hopkins Hosp. Bull. 105: 133-162.

RASMUSSON, D.D., DYKES, R.W. and HOELTZELL, P.B. (1979) Segregation of modality and submodality information in SI cortex of cat. Brain Res. 166: 409-412.

ROSEN, I. and SJOLUND, B. (1973) Organization of group I activated cells in the main and external cuneate nuclei of the cat: Identification of muscle receptors. Exp. Brain Res. 16: 221-237.

SINCLAIR, D. (1967) Cutaneous Sensation Oxford University Press, London. pp. 306.

STRETAVAN, D. and DYKES, R.W. (1980) Receptive field sequences in the somatosensory cortex of the cat. Soc. Neurosci. Abst. 6: 763 .

STONE, J., DREHER, B. and LEVENTHAL, A. (1979) Hierarchical and parallel mechanisms in the organization of visual cortex. Brain Res. Rev. 1: 345-394.

SUR, M., MERZENICH, M.M., and KAAS, J.H. (1980) Some quantitative features of the body surface representations in areas $3 b$ and 1 of somatosensory cortex in owl monkeys: magnification, receptive field area and hypercolumn size. J. Neurophysiol. 44: 295 311.

SUR, M., NELSON, R.J. and KAAS, J.H. (1978) The representation of the body surface in somatosensory area I of the grey squirrel. J. Comp. Neurol. 179: 425-449.

SUR, M., NELSON, R.J. and KAAS, J.H. (1980) Representation of the body surface in somatic koniocortex in the Prosimian Galago. J. Comp. Neurol. 189: 381-402. 
TANJI, D.G., WISE, S.P., DYKES, R.W. and JONES, E.G. (1978) Cytoarchitecture and thalamic connectivity of the third somatosensory area of the cat cerebral cortex. $J$. Neurophysiol. 41: 268-284.

TASKER, R.R. (1960) A third somatic tactile sensory area. Physiologist 3: 162.

WELKER, C. (1971) Microelectrode delineation of fine grain somatotopic organization of SMI cerebral neocortex in albino rat. Brain Res. 26: 259-275.

WELT, C., ASCHOFF, J.C., KAMEDA, K. and BROOKS, V.B. (1967) Intracortical organization of cat's motorsensory neurons.
In: Neurophysiological Basis of Normal and Abnormal Motor Activities. pp. 255-293. eds. M.D. Yahr, and D.P. Purpura. Raven Press, Hewlett, N.Y.

WILLIS, W.D. and COGGESHALL, R.E. (1978) Sensory Mechanisms of the Spinal Cord Plenum Press, New York, N.Y. pp. 485.

WOOLSEY, C.N. (1958) Organization of somatic sensory and motor areas of the cerebral cortex. In: Biological and Biochemical Bases of Behavior. pp. 63-81. eds. H.F. Harlow and C.N. Woolsey. The University of Wisconsin Press, Madison.
WOOLSEY, C.N. (1964) Cortical localization as defined by evoked potential and electrical stimulation studies. In: Cerebral Localization and Organization, pp. 17-26. eds. G. Schaltenbrand and C.N. Woolsey, The University of Wisconsin Press, Madison.

WOOLSEY, C.N. and FAIRMAN, D. (1946) Contralateral, ipsilateral and bilateral representation of cutaneous receptors in somatic areas I and II of the cerebral cortex of pig, sheep and other mammals. Surgery. 19: 684-702. 